\title{
THE FRAMEWORK ON MULTI-SCALE LANDSLIDE HAZARD EVALUATION IN CHINA
}

\author{
W.Y. Li ${ }^{a *}$, C. Liu ${ }^{\text {b }}$, J. Gao ${ }^{\text {a }}$ \\ a Institute of Urban Study, Shanghai Normal University, Shanghai, China - 1wy_326@126.com \\ ${ }^{\mathrm{b}}$ College of Surveying and Geo-Informatics, Tongji University, Shanghai, China - liuchun@tongji.edu.cn
}

Commission WG VIII/1

KEY WORDS: Scale, Framework, Landslide susceptibility, Physically based model, Process, Evaluation

\begin{abstract}
:
Nowadays, Landslide has been one of the most frequent and seriously widespread natural hazards all over the world. How landslides can be monitored and predicted is an urgent research topic of the international landslide research community. Particularly, there is a lack of high quality and updated landslide risk maps and guidelines that can be employed to better mitigate and prevent landslide disasters in many emerging regions, including China. This paper considers national and regional scale, and introduces the framework on combining the empirical and physical models for landslide evaluation. Firstly, landslide susceptibility in national scale is mapped based on empirical model, and indicates the hot-spot areas. Secondly, the physically based model can indicate the process of slope instability in the hot-spot areas. The result proves that the framework is a systematic method on landslide hazard monitoring and early warning.
\end{abstract}

\section{INTRODUCTION}

Under circumstances of global climate change, tectonic stress and human effect, landslides are among the most frequent and severely widespread natural hazards on earth, as demonstrated in the World Atlas of Natural Hazards (McGuire et al, 2004). Every year, landslide activities cause serious economic loss as well as casualties (Róbert et al, 2005). Particularly in China, some people face the most serious landslides that cause the human deaths and economic costs (Petley, 2012). The landslide hot-spot areas are located in the southwest of China (Liu et al, 2013). These areas include weak lithology, steep mountains, loose soil texture, and drastic fault zones.

Since the 1950s, landslide events have been recorded in the statistical yearbooks, newspapers, and monographs in China. As disasters have been increasingly concerned by the government and the public, information about landslide events is becoming available from online news reports (Liu et al, 2012). Some cyber China's landslide inventory database has been developed (Li et al, 2016). With a large number of landslide historical records, some empirical statistical methods can indicate the potential landslide spatio-temporal distribution (Kirschbaum et al, 2010; Petley, 2012; Damm \& Klose, 2015). However, not considering the landslide mechanism, these studies may not be a scientific basis for landslide monitoring and prediction.

Landslide susceptibility can reveal the potential landslide areas by internal factors empirical combination (Hong et al, 2007). Landslide physically based models can simulate the process of slope instability in some regional scale (Baum et al, 2002). In other words, combing with landslide susceptibility and regional landslide simulation analysis, the result should show where and when landslides may occur. In this paper, we introduce a framework on the combination of empirical and physical landslide model to map landslide hazard in China.

\section{THE METHOD ON FRAMEWORK OF MULTI- SCALE LANDSLIDE HAZARD EVALUATION}

Figure 1 shows the systematic structure of the framework.

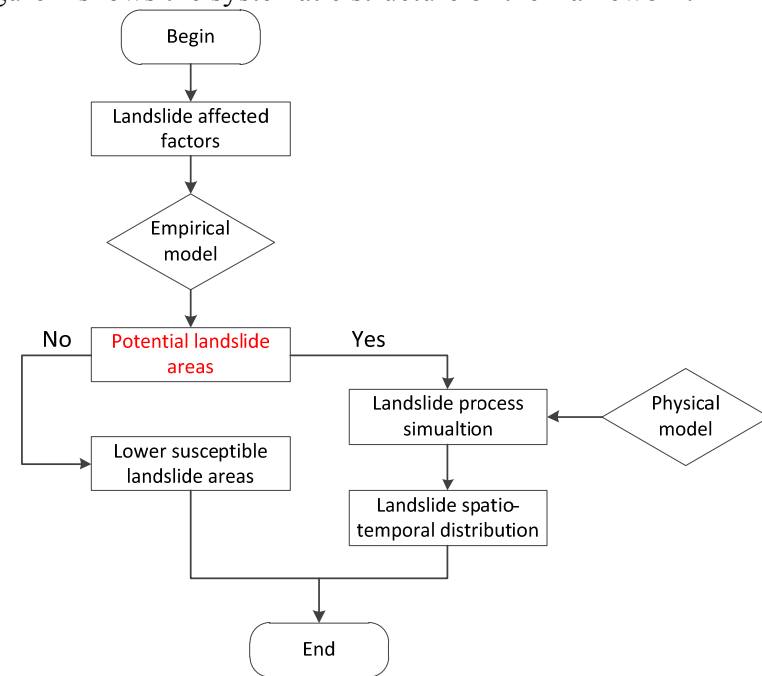

Figure 1. The systematic framework on multi-scale landslide hazard evaluation

From the 'begin' to end, firstly, the landslide affected factors are inputted. The factors include internal and external factors, such as lithology, geomorphology, slope factors, vegetation cover, potential fault zone, and rainfall, earthquake, flood, etc.

Using the empirical model, we can calculate the weight of every factor and map the landslide susceptibility combing the different factors. The result of landslide susceptibility can show the potential landslide areas. These areas may cause the landslide occurring when is induced by some external factors, such as rainfall, earthquake, flood, and human causing. In some cases, the comprehensive external factors cause landslide

\footnotetext{
${ }^{*}$ W. Y. Li (1983-), male, doctor of engineering, main research interests- remote sensing data processing and disaster evaluation
} 
occurrence together. In the potential landslide areas, the further analysis can simulate the landslide process by the physical model. For instance, the rainfall as an important external factor causes the driving forces to induce the landslide occurrence, by increasing pore water pressures and decreasing soil cohesion in the subsurface.

The rainfall-induced landslide physically based model can simulate the landslide process and map the landslide spatiotemporal distribution in the potential landslide areas. The whole framework mainly includes two parts: landslide susceptibility can show the place where landslide may occur; and landslide simulation can indicate the time.

\section{A CASE STUDY USING THE FRAMEWORK}

Landslide susceptibility is the first and most important step to indicate 'Where' landslide occurs, and provides information about the spatial distribution of potential slope instability. In our previous work, we used BP ANN method to catch the weights of the nine landslide affected factors (lithology, convexity, slope gradient, slope aspect, elevation, soil property, vegetation coverage, flow, fracture), and mapped China's landslide susceptibility (Liu et al, 2013). The result shows that most of high-susceptibility areas are located in the southeast, and the main provinces include Sichuan, Guizhou, Guangxi, Yunnan (Figure 2). Figure 2 shows China's landslide susceptibility map which is classified into five categories: 1very low; 2-low; 3-moderate; 4-high; 5-very high susceptibility. High-susceptibility regions (4-high and 5-very high) account for $4.15 \%$ of the total.
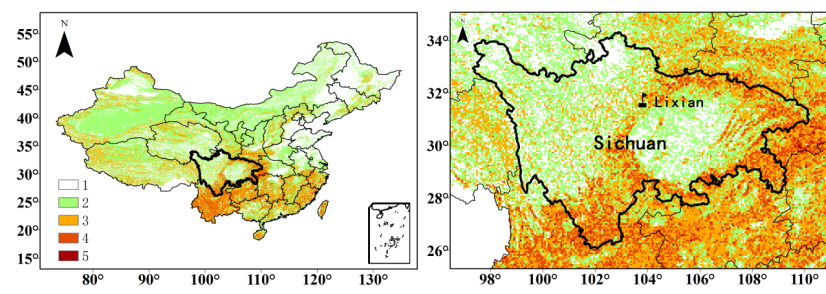

Figure 2. Landslide susceptibility in China and in Guizhou province

The right figure of Figure 2 is the landslide susceptibility in Sichuan province. As shown in the figure, the part regions of Sichuan have more susceptible to landslide occurrence in China. The ' 5.12 ' Wenchuan earthquake, Sichuan province, triggered lots of landslides and debris flows from rainfall inducing (Yin et al, 2009). In addition, numerous extension cracks were induced on hill regions near the earthquake and caused landslide activities during the heavy rains (Tang et al, 2009). Rainfall can degrade the stability of soil-rock mass and change the soil pore pressure to activate the slope failure (Kirschbaum et al, 2012).

Landslide process simulation is the second step to indicate specific 'Where' and 'When'. We select SLIDE model as the physically based model to simulate. SLIDE model is a simplified model to integrate the contribution of apparent cohesion to the shear strength of the soil and water level influenced by infiltration, and real rainstorm-induced landslide process when the surface of soil reach saturated (Liao et al, 2012).

Some assumptions are made in SLIDE model as following:

(1) The slope is considered infinite;
(2) The surface is flat and soil composition is uniform;

(3) The evapo-transpiration, underground seepage and surface flow are neglected in the water balance. Therefore, all rainfall infiltrates into the soil.

Factor of Safety (FS) is expressed as the ratio of shear strength to shear stress for evaluating slope stability. When FS $>1$, the shear strength is more than shear stress and a slope is considered stable; when FS $\leqslant 1$, a landslide can be predicted. In this model, an infinite-slope equation is translated as the cohesion and frictional components:

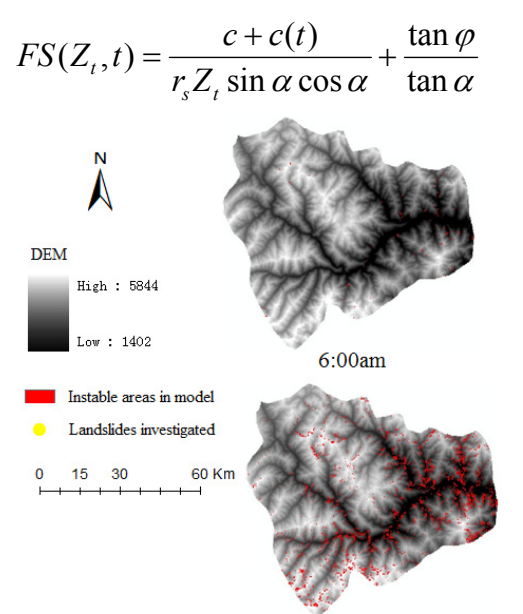

12:00am

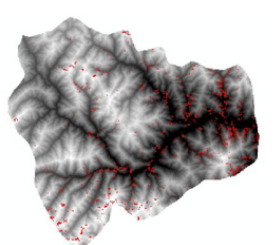

9:00am

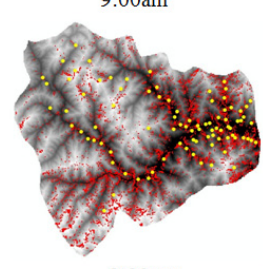

3:00pm
Figure 2 Instability maps of landslides produced by SLIDE model in four periods of Lixian County

Where $\mathrm{c}$ is soil cohesion, $\mathrm{rs}$ is the unit weight of soil, $\alpha$ is slope angle, $\varphi$ is soil surface friction angle and $\mathrm{Zt}$ is rainfall infiltration at time $t$. $c(t)$ represents the apparent cohesion at time $\mathrm{t}$ related to the matric suction based on the soil saturation (Montrasio and Valentino, 2008).

We used the model to simulate the landslide process in Lixian County. In the model, rainfall data is collected from satellitebased precipitation, TRMM data. We collected TRMM rainfall data from 6:00 am, July 5th, 2011 to 9:00 pm, July 6th, 2011 in Lixian County.

The resolutions of all layer are interpolated to $30 \mathrm{~m}$ raster grid same with DEM data. SLIDE model can calculate the change of FS values. The results show FS values of some regions reduce to below 1 at 6:00 am, July 6th, 2011, and the large-scale landslides may occur in 3:00 pm, July 6th, 2011. It matches the case of fact news reports (Figure 2). Most of landslides spread over the fracture surface of slopes in Lixian County. Particularly in the east, there are some distribution-intensive landslides.

\section{CONCLUSIONS}

This paper induces the framework to combine national landslide susceptibility and regional landslide simulation. Firstly, landslide susceptibility can indicate the potential instable areas. Secondly, physically based model can predict the time and place, when and where landslide may occur. The framework will be a basis for a systematic landslide evaluation and prediction in different scales. 


\section{ACKNOWLEDGEMENTS}

The work described in this paper is funded by National Natural Science Foundation (41501458), National Basic Research Program of China: (Project No.2013CB733204), Key Laboratory of Advanced Engineering Surveying of NASMG (TJES1010), Key Laboratory of Mining Spatial Information Technology of NASMG (KLM201309), Science Program of Shanghai Normal University (SK201525), and is also sponsored by Shanghai Gaofeng \& Gaoyuan Project for University Academic Program Development.

\section{REFERENCES}

Baum, R. L., Savage, W. Z., Godt, J. W., et al., 2002. TRIGRS: A Fortran program for transient rainfall infiltration and gridbased regional slope-stability analysis. United States Geological Survey, VA, USA

Damm, B., Klose, M., 2015. The landslide database for Germany: Closing the gap at national level. Geomorphology, 249: 82-93.

Hong, Y., Adler, R., Huffman, G., 2007. Use of satellite remote sensing data in the mapping of global landslide susceptibility. Natural Hazards, 43(2): 245-256.

Kirschbaum, D., Adler, R., Adler, D., et al., 2012. Global distribution of extreme precipitation and high-impact landslides in 2010 relative to previous years, Journal of Hydrometeorology, 13, 1536-1551.

Kirschbaum, D. B., Adler, R., Hong, Y., et al., 2010. A global landslide catalog for hazard applications: method, results, and limitations. Natural Hazards, 52(3): 561-575.

Li, W., Liu, C., Hong, Y., et al., 2016. A Public Cloud-based China's Landslide Inventory Database (CsLID): Development, Zone, and Spatiotemporal Analysis for Significant Historical Events, 1949-2011, Journal of Mountain, doi: 10.1007/s11629015-3659-7.

Liu, C., Li, W., Lu, P., et al., 2012. Susceptibility evaluation and mapping of China's landslide disaster based on multitemporal ground and remote sensing satellite data. XXII ISPRS Congress, Melbourne, Australia.

Liu, C., Li, W., Wu, H., et al., 2013. Susceptibility evaluation and mapping of China's landslides based on multi-source data. Natural Hazards, 69(3): 1477-1495.

McGuire, B., Burton, P., Kilburn, C., et al., 2004. World Atlas of Natural Hazards, Oxford University Press, London, UN.

Montrasio, L., Valentino, R., 2008. A model for triggering mechanisms of shallow landslides, Natural Hazards and Earth System Science, 8: 1149-1159.

Petley, D., 2012. Global patterns of loss of life from landslides. Geology, 40: 927-930.

Róbert, J., Javier, H., Maureen, W., 2005. Risk mapping of landslides in new member states, European Commission, Ispra, Italy.
Tang, C., Zhu, J., Li, W. L., 2009. Rainfall triggered debris flows after Wenchuan earthquake, Bulletin of Engineering Geology and the Environment, 68, 187-194.

Yin, Y. P., Wang, F. W., Sun, P., 2009. Landslide hazards triggered by the 2008 Wenchuan earthquake, Sichuan, China, Landslides, 6: 139-151. 